Check for updates

Cite this: RSC Adv., 2018, 8, 1477

\title{
Decreasing graphene synthesis temperature by catalytic metal engineering and thermal processing
}

\author{
Li Zheng, (D) *ab Xinhong Cheng, *a Peiyi Ye, ${ }^{c}$ Lingyan Shen, ${ }^{a}$ Qian Wang, (D) ab \\ Dongliang Zhang, ${ }^{\mathrm{ab}}$ Ziyue Gu, ${ }^{\mathrm{ab}}$ Wen Zhou, ${ }^{\mathrm{ab}}$ Dengpeng Wu${ }^{\mathrm{ab}}$ and Yuehui $\mathrm{Yu}^{\mathrm{a}}$
}

Chemical vapor deposition (CVD) from gaseous hydrocarbon sources has shown great promise for large-scale graphene growth, but the high growth temperature, typically $1050{ }^{\circ} \mathrm{C}$, requires precise and expensive equipment and makes the direct deposition of graphene in electronic device manufacturing processes unfeasible due to the severe physical damage to substrates. Here we demonstrate a facile route to synthesize graphene by catalytic metal engineering and thermal processing. The engineered catalytic metal (copper) with carbon implantation could lower the synthetic temperature to $700{ }^{\circ} \mathrm{C}$. And the resulting graphene shows few defects, uniform morphology and high carrier mobility, comparable to CVD graphene grown at $1050{ }^{\circ} \mathrm{C}$. This technique could expand the applications of graphene in electronic and optoelectronic device manufacturing and is compatible with conventional microelectronics technology.

Received 22nd October 2017 Accepted 24th November 2017

DOI: $10.1039 / c 7 r a 11654 c$

rsc.li/rsc-advances cost. Using less stable solid or liquid feedstock instead of methane is another approach for decreasing the CVD temperature of graphene growth. However, the flow of the pneumatolytic solid or liquid feedstock is difficult to control and most alternative feedstock such as benzene is hypertoxic. Therefore, low-temperature synthesis of graphene still remains a challenge.

In this work, we systematically analyze a facile approach to grow graphene by catalytic metal engineering prior thermal processing at a low temperature down to $700{ }^{\circ} \mathrm{C}$. The catalytic metal (copper) was engineered by carbon implantation to form $\mathrm{Cu} / \mathrm{C}$ alloys and the implanted carbon atoms acted as the feedstock for graphene synthesis. The as-deposited graphene shows few defects, uniform morphology and high carrier mobility, comparable to CVD graphene grown at $1050{ }^{\circ} \mathrm{C}$. The resulting graphene by catalytic metal engineering and thermal processing could expand the applications of graphene in electronic and optoelectronic device manufacturing and was compatible with conventional microelectronics technology.

\section{Experimental section}

\subsection{Low-temperature synthesis of graphene}

As shown in Fig. 1, the catalytic metal $(\mathrm{Cu})$ was first engineered by $\mathrm{C}$ implanting $(30 \mathrm{keV})$ and the atomic ratio of $\mathrm{Cu}$ and $\mathrm{C}$ in the

PECVD is not suitable for industrial applications due to its high

${ }^{a}$ State Key Laboratory of Functional Materials for Informatics, Shanghai Institute of Microsystem and Information Technology, Chinese Academy of Sciences, Changning Road 865, Shanghai, 200050, P. R. China. E-mail: zhengli@mail.sim.ac.cn; xh_cheng@mail.sim.ac.cn

${ }^{b}$ University of Chinese Academy of Sciences, Beijing, 100049, P. R. China

${ }^{c}$ Department of Materials Science and Engineering, University of California, Los Angeles, California, 90095, USA

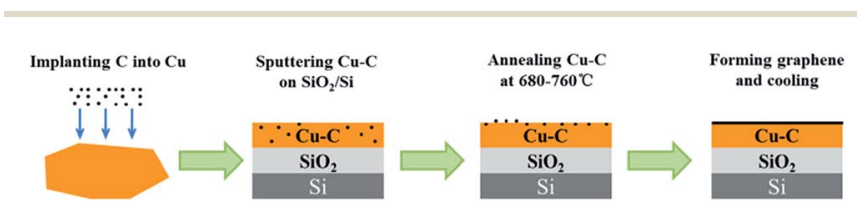

Fig. 1 The flow chart of low temperature graphene synthesis by catalytic metal engineering and thermal processing. 
obtained $\mathrm{Cu} / \mathrm{C}$ alloy was $99.06: 0.04$. Then $\mathrm{Cu} / \mathrm{C}$ alloy was deposited on $\mathrm{a} \mathrm{SiO}_{2} / \mathrm{Si}$ substrate by sputtering prior annealing. The annealing process was maintained at the designed temperatures $\left(680-760{ }^{\circ} \mathrm{C}\right)$ for $10 \mathrm{~min}$ followed by naturally cooling in an annealing furnace with $\mathrm{H}_{2}$ shielding. The low content of $\mathrm{C}$ in the alloy was due to low solubility of $\mathrm{C}$ in $\mathrm{Cu}$. In the alloy, $\mathrm{C}$ was the feedstock of graphene and $\mathrm{Cu}$ acted as the catalyst. Therefore, no external feedstock was needed for graphene synthesis. The thickness of $\mathrm{Cu}-\mathrm{C}$ film was $1.14 \mu \mathrm{m}$. The design of annealing temperatures and $\mathrm{Cu}-\mathrm{C}$ film thickness will be discussed in the theoretical calculation part.

\subsection{Graphene characterization}

The obtained graphene films were characterized by Raman spectroscopy, atomic force microscope (AFM) and high resolution transmission electron microscopy (HRTEM), respectively. The Raman measurements were carried out using a Raman spectroscopy of HORIBA Jobin Yvon HR800. All samples were excited by $\mathrm{Ar}^{+}$laser with wavelength of $514 \mathrm{~nm}$ with the spot size of $1 \mu \mathrm{m}$ in diameter. The obtained graphene film was transferred from the $\mathrm{Cu} / \mathrm{SiO}_{2} / \mathrm{Si}$ substrates onto glass slides by a PMMA-assisted wet-transfer method in order to directly evaluate the thickness of the graphene film. The $\mathrm{SiO}_{2} / \mathrm{Si}$ substrates were etched by $10 \%$ potassium hydroxide solution while $\mathrm{Cu}$ was etched by $30 \%$ iron trichloride solution. Then the cross-section microstructure of graphene on the glass was characterized by the HRTEM (JEOL-2100F). Graphene field effect transistors (GFETs) were fabricated by lithography and the device structure was detected by the scanning electron microscope (SEM) using a JEOL $7800 \mathrm{~F}$ with an accelerating voltage of $5 \mathrm{kV}$ beam. The GFETs were measured at room temperature under ambient conditions by an analytical probe station.

\section{Results and discussion}

\subsection{Theoretical calculation}

$\mathrm{Cu}-\mathrm{C}$ alloys were selected as the sputtering target in which the atomic ratio of $\mathrm{Cu}$ and $\mathrm{C}$ was $99.06: 0.04$. The thickness of deposited $\mathrm{Cu}-\mathrm{C}$ alloy could be calculated by the following equation

$$
\eta \rho \tau=\gamma
$$

where $\eta$ is the copper concentration and carbon solubility (99.96/0.04), $\rho$ is the copper atomic density $\left(8.36 \times 10^{22}\right.$ atoms per $\left.\mathrm{cm}^{3}\right), \tau$ is the $\mathrm{Cu}-\mathrm{C}$ film thickness, and $\gamma$ is the amount of carbon atoms in graphene $\left(3.8 \times 10^{15}\right.$ atoms per $\left.\mathrm{cm}^{2}\right)$. Therefore, the thickness of $\mathrm{Cu}-\mathrm{C}$ film could be calculated as $1.14 \mu \mathrm{m}$. The annealing temperature could be estimated by the following Arrhenius equation,

$$
D=D_{0} \exp \left(-\frac{\Delta G_{\mathrm{m}}}{k T}\right)
$$

where $D_{0}$ is the diffusion constant of $\mathrm{C}$ in $\mathrm{Cu}, \Delta G_{\mathrm{m}}$ is the activation energy $(0.990 \mathrm{eV})$ for the migration of the interstitial atoms, $k$ is the Boltzmann constant, and $T$ is the temperature. $D_{0}$ can be extracted from the following equation,

$$
D_{0}=\frac{1}{6} \alpha^{2} z v \exp \left(\frac{\Delta S_{\mathrm{m}}}{R}\right)
$$

where $\alpha$ is the lattice constant $(0.377 \mathrm{~nm}$ for $\mathrm{Cu}), z$ is the number of sites available (0.6), $v$ is the vibration frequency $\left(10^{15}\right.$ $\mathrm{Hz}), \Delta S_{\mathrm{m}}$ is the entropy of migration $\left(2.554 \times 10^{4} \mathrm{eV} \mathrm{K}^{-1}\right)$, and $R$ is the gas constant $\left(5.189 \times 10^{19} \mathrm{eV} \mathrm{K}^{-1}\right)$. As a result, $D_{0}$ was estimated to be $0.14 \mathrm{~cm}^{2} \mathrm{~s}^{-1}$. The thickness $(\tau)$ of $\mathrm{Cu}-\mathrm{C}$ film has been calculated as $1.14 \mu \mathrm{m}$ and the distance $\left(\tau^{\prime}\right)$ of carbon atoms need to travel is typically an order of magnitude greater than $\tau$, which can be also estimated by the following equation,

$$
\tau^{\prime} \approx \sqrt{D t}
$$

where $t$ is the diffusion time. Assuming the diffusion time is $1 \mathrm{~s}$ and combining eqn (2) and (4), the annealing temperature could be estimated as $720{ }^{\circ} \mathrm{C}$.

\subsection{Synthetic temperature verification}

The theoretical estimation of the synthetic temperature was confirmed by experiments. Fig. 2a shows the Raman spectra of graphene by annealing $\mathrm{Cu} / \mathrm{C}$ alloys at different temperatures $\left(680-760{ }^{\circ} \mathrm{C}\right)$. The main features in the Raman spectrum of graphene are the $\mathrm{G}$ and $2 \mathrm{D}$ peaks, lying at around $1580 \mathrm{~cm}^{-1}$ and $2700 \mathrm{~cm}^{-1}$, respectively. The $\mathrm{G}$ peak corresponds to optical $\mathrm{E}_{2 \mathrm{~g}}$ phonons at the Brillouin zone center $(T)$, whereas the 2D peak originates from a process where momentum conservation is satisfied by two phonons with opposite wave vectors. ${ }^{18-21}$ Therefore, no defects are required for the activation of $2 \mathrm{D}$ peak, and it thus always presents. The D peak lying at around $1300 \mathrm{~cm}^{-1}$ is due to the breathing modes of six-member rings and requires a defect for its activation. ${ }^{21-23}$ Defects, which include structural disorder such as grain boundaries or vacancies, edges, and functionalized groups, have the effect of increasing $\mathrm{D}$ peak intensity $\left(I_{\mathrm{D}}\right)$, decreasing $2 \mathrm{D}$ band intensity $\left(I_{2 \mathrm{D}}\right)$ and broadening the $2 \mathrm{D}$ full width at half-maximum (FWHM). As shown in Fig. 2a and $b$, the intensity ratio of $\mathrm{D}$ peak and $\mathrm{G}$ peak $\left(I_{\mathrm{D}} / I_{\mathrm{G}}\right.$ ratio) rises
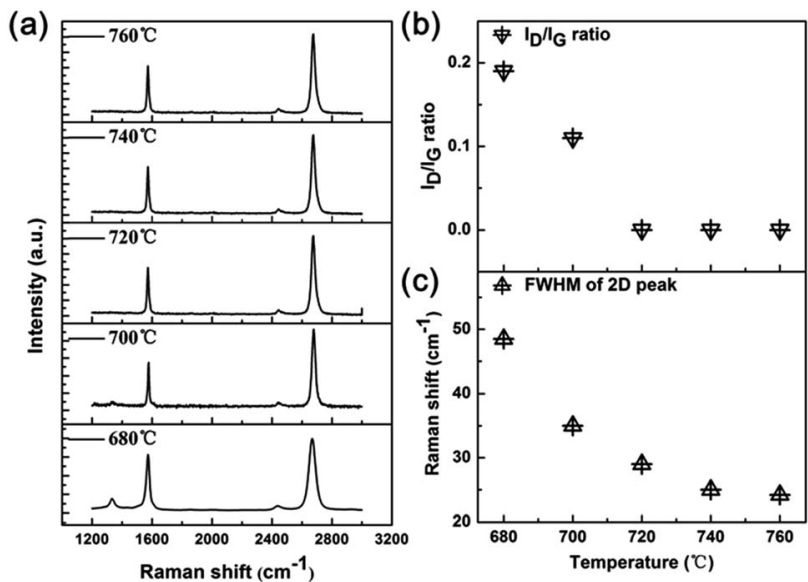

Fig. 2 (a) Raman spectra of graphene by annealing $\mathrm{Cu} / \mathrm{C}$ alloys at $680-720^{\circ} \mathrm{C}$. (b) The $I_{\mathrm{D}} / /_{\mathrm{G}}$ ratio of graphene by annealing $\mathrm{Cu} / \mathrm{C}$ alloys at $680-720^{\circ} \mathrm{C}$. (c) The FWHM of 2D peak of graphene by annealing $\mathrm{Cu} / \mathrm{C}$ alloys at $680-720^{\circ} \mathrm{C}$. 

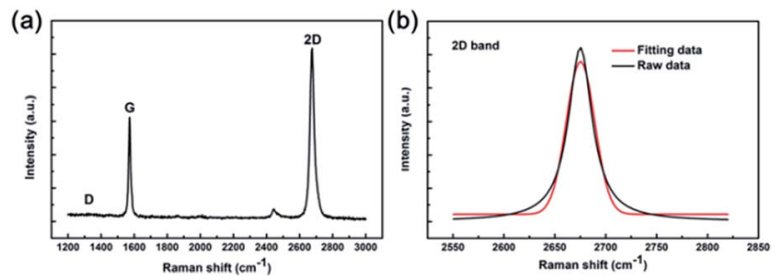

(c)

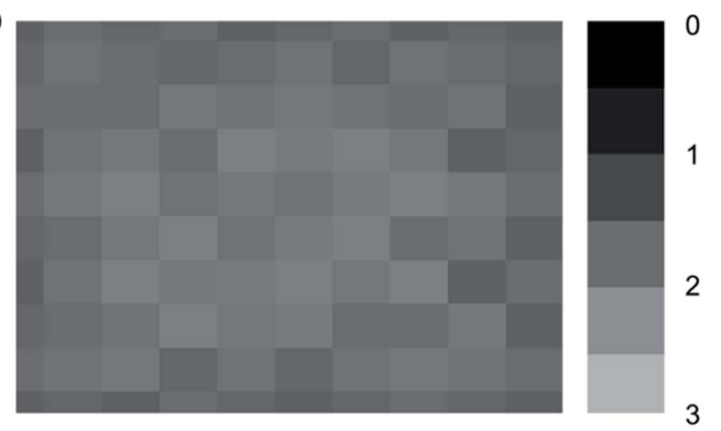

Fig. 3 (a) Raman spectrum of graphene by catalytic metal (Cu) engineering and thermal processing at $700^{\circ} \mathrm{C}$. (b) $2 \mathrm{D}$ band can be split into single Lorentzian curve (red curve). (c) Two-dimensional Raman mapping of the graphene film. The gradient bar to the right of each map represents the $I_{2 D} / I_{G}$ band ratio.

with annealing temperature increases. When the annealing temperature increases to $700{ }^{\circ} \mathrm{C}$, the $\mathrm{D}$ peak is not distinct, and when the annealing temperature increases to $720^{\circ} \mathrm{C}$, the $\mathrm{D}$ peak is undetectable, indicating the synthesized graphene films is in high quality comparable to that of CVD graphene grown at $1050{ }^{\circ} \mathrm{C} .{ }^{11-15}$ In addition, the $2 \mathrm{D}$ band is symmetric and its full width at half maximum (FWHM) is down to $\sim 35 \mathrm{~cm}^{-1}$ when the temperature is $700{ }^{\circ} \mathrm{C}$, which is in consistent with monolayer graphene. ${ }^{21}$ The FWHM of $2 \mathrm{D}$ peak can be further decreased by rising the annealing temperature (Fig. 2c).

Fig. 3a depicts the representative Raman spectrum of the asdeposited graphene by annealing $\mathrm{Cu} / \mathrm{C}$ alloys at $700{ }^{\circ} \mathrm{C}$. The defect-related $\mathrm{D}$ band is negligible, implying that the graphene film has few defects or disorder. Furthermore, as shown in Fig. $3 \mathrm{~b}$, the symmetric $2 \mathrm{D}$ band with a FWHM of $35 \mathrm{~cm}^{-1}$ can be well fitted by a single Lorentzian curve providing evidence of monolayer graphene. ${ }^{21}$ To determine the quality, uniformity, and thickness of the graphene films deposited on a large-scale substrate, Raman mapping of the $2 \mathrm{D}$ to $\mathrm{G}$ peak intensity ratio over a $10 \mu \mathrm{m} \times 10 \mu \mathrm{m}$ area with a spot size of $1 \mu \mathrm{m}$ and a step size of $1 \mu \mathrm{m}$ is performed, as shown in Fig. 3c. The $I_{2 \mathrm{D}} / I_{\mathrm{G}}$ ratio is quite uniform over the region investigated and the $I_{2 \mathrm{D}} / I_{\mathrm{G}}$ ratio is in the range of 1.5-2, indicating complete monolayer graphene coverage in the scanned area. Those measurements give evidence of the high crystal quality in graphene samples and indicate the graphene resultant temperature can be down to $700{ }^{\circ} \mathrm{C}$ by catalytic metal $(\mathrm{Cu})$ engineering and thermal processing.

\subsection{Characterization analysis}

The surface morphology of transferred graphene on a $\mathrm{SiO}_{2} / \mathrm{Si}$ substrate has been investigated by AFM (Fig. 4a). The surface rootmean-square (RMS) roughness is down to $0.4 \mathrm{~nm}$, manifesting the high uniformity and flatness of graphene deposited by catalytic (a)
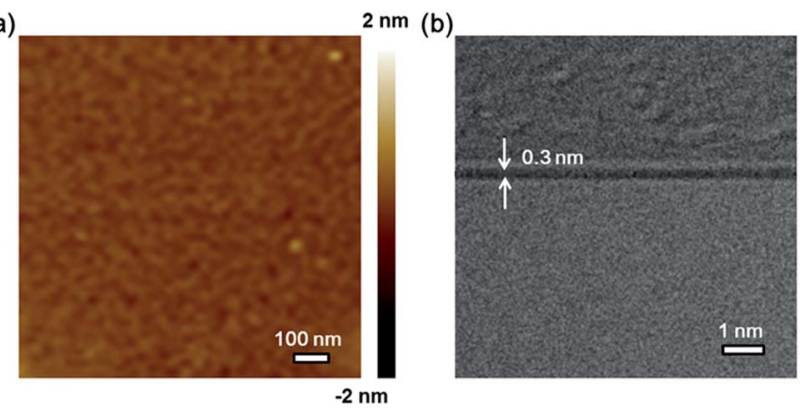

Fig. 4 (a) The AFM image of transferred graphene on a $\mathrm{SiO}_{2} / \mathrm{Si}$ substrate. (b) The HRTEM image of graphene shows its monolayer property.
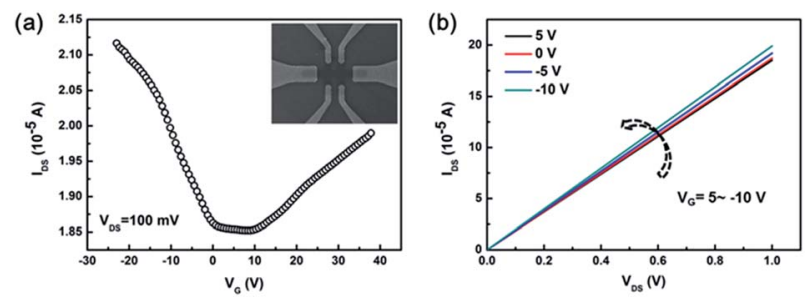

Fig. 5 (a) The $I_{D S}-V_{G}$ curve of the graphene transistor at $V_{D S}=$ $100 \mathrm{mV}$. The inset shows the SEM image of a back-gated GFETs. (b) The $I_{D S}-V_{D S}$ curves of the graphene transistor with different $V_{G}$.

metal $(\mathrm{Cu})$ engineering and thermal processing. The as-deposited graphene film has also been transferred onto TEM grids by a polymethyl methacrylate (PMMA)-assisted wet-transfer method in order to directly evaluate the thickness of the graphene film as shown in Fig. 4b. The cross-section microstructure of graphene characterized by HRTEM shows its thickness is $0.3 \mathrm{~nm}$, further demonstrating the as-deposited graphene is monolayer.

To determine the transport properties of the synthesized graphene film, the back-gated GFET has been fabricated on the $\mathrm{SiO}_{2}$ $(300 \mathrm{~nm}) / \mathrm{Si}$ substrates. The SEM image of GFET is shown in the inset of Fig. 5a. The highly reproducible transfer characteristics $\left(I_{\mathrm{DS}}-V_{\mathrm{G}}\right)$ of the GFET measured at room temperature under ambient conditions is shown in Fig. 5a. The typical $I_{\mathrm{DS}}-V_{\mathrm{G}}$ curve measured at a $V_{\mathrm{DS}}$ of $100 \mathrm{mV}$ shows that the gate can cause either hole or electron conduction. The V-shaped ambipolar transfer characteristic is typical of monolayer graphene with a zero bandgap. ${ }^{24-33}$ The Dirac point of the GFET shifts slightly to a positive gate at $V_{\mathrm{G}}=5 \mathrm{~V}$, demonstrating slight p-type hole doping performance. The slight p-type doping of graphene is due to the charge transfer doping by the adsorption of atmospheric hole dopants $\left(\right.$ e.g. $\left.\mathrm{O}_{2}\right)$ in air. ${ }^{34-37}$ In addition, the residue of PMMA may also lead to p-type doping of graphene. ${ }^{37,38}$ According to the two slopes of the linear regions on both sides of the V-shaped curve, the hole mobility $\left(\mu_{\mathrm{h}}\right)$ is $\sim 1200 \mathrm{~cm}^{2} \mathrm{~V}^{-1} \mathrm{~s}^{-1}$ and the electron mobility $\left(\mu_{\mathrm{e}}\right)$ is $\sim 1100 \mathrm{~cm}^{2} \mathrm{~V}^{-1} \mathrm{~s}^{-1}$, both of which are comparable to values reported recently from transferred CVD graphene. ${ }^{24-33}$ The presence of defects, wrinkles, and overlaps generated from the transfer process may degrade the performance of GFETs, thus underestimating the carrier mobility of the synthesized graphene film. In the output characteristics of the GFET, as shown in Fig. 5b, 
the linear $I_{\mathrm{DS}}-V_{\mathrm{DS}}$ behavior indicates a good ohmic contact between the $\mathrm{Au} / \mathrm{Ti}$ contact and graphene channels. In addition, $I_{\mathrm{DS}}$ increases with $V_{\mathrm{G}}$ negative shift from 5 to $-10 \mathrm{~V}$ and it is indicative of p-type behavior as well. The electrical transport data also reveal that the graphene deposited by catalytic metal $(\mathrm{Cu})$ engineering and thermal processing is of good quality which can be further improved by refining the transfer process.

\section{Conclusions}

In summary, catalytic metal engineering by implanting $\mathrm{C}$ into $\mathrm{Cu}$ and thermal processing were established to deposit graphene at a low temperature down to $700{ }^{\circ} \mathrm{C}$. Parametric studies show that the superior quality and homogeneous monolayer graphene in large scale can be directly achieved on the $\mathrm{Cu} / \mathrm{C}$ substrates. Raman, AFM and HRTEM are utilized to determine both the quality and thickness of the graphene film. GFETs were designed and characterized to measure the electrical properties of the synthesized graphene film. The obtained graphene by catalytic metal engineering and thermal processing is scalable and compatible with the mainstream microelectronics technology, thus paving the way to the application of graphene in microelectronic field at a low temperature.

\section{Conflicts of interest}

There are no conflicts to declare.

\section{Acknowledgements}

This work was supported by the Shanghai Sailing Program (Grant No. 17YF1422700) and the National Scientific Foundation of Shanghai (Grant No. 16ZR1442300). We would like to thank Prof. Xiaoming Xie, Prof. Ya-Hong Xie, Prof. Zengfeng Di, A. Prof. Yan Cheng, Dr Tianbo Wang, Dr Zirui Liu, Dr Jimmy Ng, Dr Owen Liang, Dr Ming Xia, Dr Xinke Yu and Dr Zhongbo Yan for their generous help.

\section{References}

1 A. K. Geim and K. S. Novoselov, Nat. Mater., 2007, 6, 183.

2 K. S. Novoselov, A. K. Geim, S. V. Morozov, D. Jiang, Y. Zhang, S. V. Dubonos, I. V. Grigorieva and A. A. Firsov, Science, 2004, 306, 666.

3 K. S. Novoselov, A. K. Geim, S. V. Morozov, D. Jiang, M. I. Katsnelson, I. V. Grigorieva, S. V. Dubonos and A. A. Firsov, Nature, 2005, 438, 197.

4 M. S. Fuhrer, Science, 2013, 340, 1413.

5 J. H. Chen, C. Jang, S. Xiao, M. Ishigami and M. S. Fuhrer, Nat. Nanotechnol., 2008, 3, 206.

6 Y.-M. Lin, C. Dimitrakopoulos, K. A. Jenkins, D. B. Farmer, H.-Y. Chiu, A. Grill, et al., Science, 2010, 323, 662.

7 X. Li, Y. Zhu, W. Cai, M. Borysiak, B. Han, D. Chen, et al., Nano Lett., 2009, 9, 4359.

8 B. Y. Zhang, T. Liu, B. Meng, X. Li, G. Liang, X. Hu, et al., Nat. Commun., 1811, 2013, 4.

9 S. Basu and P. Bhattacharyya, Sens. Actuators, B, 2012, 173, 1.
10 S.-H. Pan, H. Medina, S.-B. Wang, L.-J. Chou, Z. M. Wang, K.-H. Chen, et al., Nanoscale, 2014, 6, 8635.

11 Y. Wu, Y. Hao, H. Y. Jeong, Z. Lee, S. Chen, W. Jiang, et al., Adv. Mater., 2013, 25, 6744.

12 Q. Li, H. Chou, J. H. Zhong, J. Y. Liu, A. Dolocan, J. Zhang, et al., Nano Lett., 2013, 13, 486.

13 X. Li, W. Cai, L. Colombo and R. S. Ruoff, Nano Lett., 2009, 9, 4268.

14 S. Bhaviripudi, X. Jia, M. S. Dresselhaus and J. Kong, Nano Lett., 2010, 10, 4128.

15 Y. Wu, Y. Hao, H. Y. Jeong, Z. Lee, S. Chen, W. Jiang, et al., Adv. Mater., 2013, 25, 6744.

16 R. John, A. Ashokreddy, C. Vijayan and T. Pradeep, Nanotechnology, 2011, 22, 165701.

17 L. Xie, L. Jiao and H. Dai, J. Am. Chem. Soc., 2010, 132, 14751. 18 L. Zheng, X. Cheng, D. Cao, G. Wang, Z. Wang, D. Xu, et al., ACS Appl. Mater. Interfaces, 2014, 6, 7014.

19 L. Zheng, X. Cheng, D. Cao, Z. Wang, C. Xia, Y. Yu, et al., Appl. Phys. Lett., 2014, 104, 023112.

20 D. C. Elias, R. R. Nair, T. M. G. Mohiuddin, S. V. Morozov, P. Blake, M. P. Halsall, et al., Science, 2009, 323, 610.

21 A. C. Ferrari and D. M. Basko, Nat. Nanotechnol., 2013, 8, 235.

22 A. C. Ferrari and J. Robertson, Phys. Rev. B: Condens. Matter Mater. Phys., 2000, 61, 14095.

23 K. K. Mani and R. Ramani, Phys. Status Solidi B, 1974, 61, 659.

24 V. Singh, D. Joung, L. Zhai, S. Das, S. I. Khondaker and S. Seal, Prog. Mater. Sci., 2011, 56, 1178.

25 S. Bhaviripudi, X. Jia, M. S. Dresselhaus and J. Kong, Nano Lett., 2010, 10, 4128.

26 R. John, A. Ashokreddy, C. Vijayan and T. Pradeep, Nanotechnology, 2011, 22, 165701.

27 M. Zhu, Z. Du, Z. Yin, W. Zhou, Z. Liu, S. H. Tsang, et al., ACS Appl. Mater. Interfaces, 2016, 8, 502.

28 R. Munoz and C. Gomez-Aleixandre, Chem. Vap. Deposition, 2013, 19, 297.

29 I. A. Kostogrud, K. V. Trusov and D. V. Smovzh, Adv. Mater. Interfaces, 2016, 3, 1500823.

30 S. J. Chae, F. Güneş, K. K. Kim, E. S. Kim, G. H. Han, S. M. Kim, et al., Adv. Mater., 2009, 21, 2328.

31 V. K. Sangwan, D. Jariwala, S. A. Filippone, H. J. Karmel, J. E. Johns, J. M. Alaboson, et al., Nano Lett., 2013, 13, 1162.

32 S. K. Lee, H. Y. Jang, S. Jang, E. Choi, B. H. Hong, J. Lee, et al., Nano Lett., 2012, 12, 3472.

33 L. Wang, X. Chen, Y. Wang, Z. Wu, W. Li, Y. Han, et al., Nanoscale, 2013, 5, 1116.

34 S. Ryu, L. Liu, S. Berciaud, Y. J. Yu, H. Liu, P. Kim, et al., Nano Lett., 2010, 10, 4944.

35 L. Zheng, X. Cheng, Z. Wang, C. Xia, D. Cao, L. Shen, et al., J. Phys. Chem. C, 2015, 119, 5995.

36 D. W. Boukhvalov and M. I. Katsnelson, J. Phys. Chem. C, 2009, 113, 14716.

37 U. N. Maiti, W. J. Lee, J. M. Lee, Y. Oh, J. Y. Kim, J. E. Kim, et al., Adv. Mater., 2014, 26, 40.

38 W. J. Yu, L. Liao, S. H. Chae, Y. H. Lee and X. Duan, Nano Lett., 2011, 11, 4759. 